\title{
Bioanalytical HPLC method of Piper betle L. for quantifying phenolic compound, water-soluble vitamin, and essential oil in five different solvent extracts
}

\author{
Rayudika Aprilia Patindra Purba*, Pramote Paengkoum \\ School of Animal Technology and Innovation, Institute of Agricultural Technology, Suranaree University of Technology, Nakhon Ratchasima, Thailand.
}

\begin{tabular}{l}
\hline ARTICLE INFO \\
\hline Received on: 02/01/2019 \\
Accepted on: $17 / 03 / 2019$ \\
Available online: 08/05/2019
\end{tabular}

\section{Key words:}

Phenolic compounds, flavonoids, essential oil, Piper betle L., gradient HPLC, different solvent extracts.

\begin{abstract}
A reversed-phase high-performance liquid chromatography with diode-array detection (HPLC-DAD) was developed and validated to estimate the phenolic acids (gallic acid, caffeic acid, syringic acid, p-coumaric acid, sinapic acid, and ferrulic acid), flavonoids (catechin rutin, myricetin, quercetin, apigenin, and kaempferol), ascorbic acid, and eugenol. The chromatogram condition was set in suitable wavelength $272 \mathrm{~nm}$ and run flow rate $0.7 \mu 1 /$ minutes using HPLC Agilent Technologies 1260 Infinity, a reversed-phase Zorbax SB-C18 column (3.5 $\mu$ m particle size, i.d. $4.6 \mathrm{~mm} \times 250$ $\mathrm{mm}$ ) with the mobile phase solution (1:9, HPLC-grade acetonitrile: $1 \%$ acetic acid). The linearity, precision, limit of detection, limit of detection, and accuracy were $R^{2}>0.9907$, relative standard deviation $<1 \%, 0.005 \mu \mathrm{g} / \mathrm{ml}, 0.015 \mu \mathrm{g} /$ $\mathrm{ml}$, and $96 \%-102 \%$, respectively. As a result, all the selective compounds were successfully separated, identified, and quantified. The enormous contents were found in quercetin and eugenol, expressing crude content (mean, $5.989 \mathrm{mg} / \mathrm{g}$ ) and residue content (mean, $1.934 \mathrm{mg} / \mathrm{g}$ ) for quercetin, while crude content (mean, $3.209 \mathrm{mg} / \mathrm{g}$ ) and residue content (mean, $0.184 \mathrm{mg} / \mathrm{g}$ ) for eugenol. Consequently, this method could be applied, repeated, and developed for the later observation, especially in commercially inclination of Piper betle analysis.
\end{abstract}

\section{INTRODUCTION}

Regarding pharmaceutical development inviting utilization of organic compounds is broadly critical issue for human health properties, even more in animal welfare. Phenolic compounds, or commonly as polyphenols, had been considered as rife organic compound characteristic, ubiquitously in plants, fruits, and vegetables. These are secondary metabolites that contain simple phenolic molecules and benzene rings through shikimic and pentose phosphate pathway. Lin et al. (2016) reviewed polyphenols have a host of medicine values, such as anti-inflammatory, antioxidant, antidiabetic, and anticarcinogenic, representing action by its members: simple flavonoid, phenolic

\section{${ }^{*}$ Corresponding Author}

Rayudika Aprilia Patindra Purba, School of Animal Technology and Innovation, Institute of Agricultural Technology, Suranaree University of Technology, Nakhon Ratchasima, Thailand.

E-mail: rayudikaapp.007@gmail.com acid, complex flavonoid, and hydroxycinnamic acid. The interaction of polyphenols with neighborhood substances and its derivative had been linked to specifically other functions. For instances, polyphenols persuading essential oil as eugenol had been used revealing antimicrobial mode and stress-linked phytochemical corresponding to water-soluble vitamin profoundly as ascorbic acid. Hence, elaborating study to obtain, extract, and modulate a comprehensive knowledge whether using single polyphenols or combining with other essential compounds should be more investigated.

In earlier study, Begam et al. (2018) reported that the ethanol Piper betle L. extraction bring up 10 major fractions, leaded by eugenol using gas chromatography-mass spectrometry procedure. Moreover, Syahidah et al. (2017) confirmed that the Piper betle L. has an abundant of flavonoids, tannins, and alkaloids where the methanolic assay was subjected under high-performance liquid chromatography with diode-array detection (HPLCDAD) machine. Hence, elaborating study to obtain, extract, and modulate a comprehensive knowledge whether (about) using 
single polyphenols or combining with other essential compounds should be more investigated.

Piper betle Linn. (Family: Piperaceae) is herb plant(Fig. 1) whose has a perennial dioecious, semi-woody climber, and swollen stems. Its common names are betel (English), paan (Indian), phlu (Thai), and sirih (Bahasa Indonesian). Piper betle L. is cultivated in tropical Asian area and has a strong pungent aromatic flavor. The plant is credited for conventional treatments covering antiseptic, antimicrobial, and medicinally useful for pulmonary affection by locals. In addition, nutrient value of this plant was categorized as low protein $(3.5 \%-3.94 \%)$, fat $(0.25 \%-0.33 \%)$, and energy 21.8 $\mathrm{MJ} / \mathrm{kg}$ (unpublished data). Dasgupta and De (2004) conducted in vitro study used Piper betle extracts exhibiting antioxidant role and Datta et al. (2011) reported ethanol extract of Piper betle had confirmed diminishing significantly toward to human pathogenic bacteria (Gram-positive and Gram-negative). As a result, we hypothesized that the natural organic compound of Piper betle L. and corroboration method for compelling its interaction were suspected necessary for further study.

Therefore, quantification of natural present contents and validation method, including separation and identification of active constituents was a prerequisite. Hopefully, the actual sentence of these results could be clear-cut and useful for pharmaceutical biotechnology community, human nutrition, and animal welfare group. Thus, the aim was to identify and measure phenolic compound, water-soluble vitamin, and essential oil of Piper betle L. leaf as potential antioxidant, antimicrobial, and anticarcinogenic using different polarity of solvents by reverse phase HPLC-DAD.

\section{MATERIALS AND METHODS}

\section{Plant material}

Piper betle L. leaves were purchased from local market, Prachinburi area, East Thailand. Fresh biomass of leafy material plant was pooled, rinsed, and kept overnight at $4^{\circ} \mathrm{C}$. Residue content of Piper betle L. leaves was made by after steamdistillation using Clevenger's apparatus to collect an essential oil (separated report) and the crude content of Piper betle L. leaves was as untreated steam-distillation. The crude and residue content were air-dried using oven set $40^{\circ} \mathrm{C}$ for 2 days, made a powder, and kept in sealed plastic until the extraction time.

\section{Extraction}

Five grams of crude or residue content were extracted with $20-\mathrm{ml}$ solvents on the basis of their polarity. Water, methanol, ethanol, chloroform, and hexane were used in this section. The extraction were run with Soxhlet apparatus for 3-4 hours. The extract was filtered and kept. Remaining solid residue on the filter paper was reextracted for three times with volume of fresh solvent, Soxhlet, and filtered. All the filtrates were pooled and combined based on the solvent followed by evaporation using Rotavapor (Buchi R300). The extracts were finally filtered through 0.45 $\mu \mathrm{m}$ PVDF syringe paper and the volume was made up to $10 \mathrm{ml}$ using the same solvent and stored at $-20^{\circ} \mathrm{C}$.

\section{Chemical and reagent}

The HPLC-grade solvents were purchased from Anapure (Bangkok, Thailand) for acetic acid, Avantor (USA) for ethanol and methanol, Labscan (Bangkok, Thailand) for hexane and chloroform, and Duksan (Gyunggido, Korea) for Acetonitrile. Standard chemicals, phenolic acids (gallic, caffeic, syringic, p-coumaric, ferulic, and sinapic acid), flavonoids (catechin, rutin, myricetin, quercetin, apigenin, and kaempferol), and essential oil (eugenol) were purchased from Sigma Chemical Co. (St. Louis, MO). However, ascorbic acid was purchased from Carlo erba (Strada Rivoltana, France). All water used in all the preparations was of the double distillated water grade (Millipore, Illkirch-Graffenstaden, France).

\section{Standard chemical preparation and HPLC equipment}

A standard stock solution $(1 \mathrm{mg} / \mathrm{ml})$ was made by diluted $1 \mathrm{mg}$ selecting standard with $0.5-\mathrm{ml}$ HPLC-grade methanol followed by sonication for 15 minutes in ice and vortex. The standard stock solution was then adjusted to $1 \mathrm{ml}$ with the mobile phase solution (1:9, HPLC-grade acetonitrile: $1 \%$ acetic acid).

HPLC analyses were performed with HPLC Agilent Technologies 1260 Infinity (USA and Canada) with four solvent delivery system quaternary pumps (61311B), including a diode array detector (DAD 61315D) with 10-mm flow cell, an automatic sample injection valve equipped with a 100 loop and Agilent OpenLAB CDS 1.8.1 system manager as data processor. The separation was achieved by a reversed-phase Zorbax SB-C18 column $(3.5 \mu \mathrm{m}$ particle size, i.d. $4.6 \mathrm{~mm} \times 250 \mathrm{~mm})$.

\section{Chromatographic condition}

A method for chromatographic analysis followed to Seal (2016) with modification. The gradient elution, flow rate, and temperature setting are presented in Table 1. Injected volume was maintained at $20 \mu \mathrm{l}$. A photo diode array UV detector run wavelength at $272 \mathrm{~nm}$ according to absorption maxima of analyzed compounds was set to detect HPLC chromatogram with analysis total time per sample 65 minutes. Identification of each compound was decided with identical condition by its retention time inviting

Table 1. Chromatographic design for gradient eluent, flow rate, and temperature.

\begin{tabular}{|c|c|c|c|c|}
\hline \multirow{2}{*}{ Time (minutes) } & \multirow{2}{*}{ Flow rate $(\mu \mathrm{l} /$ minutes $)$} & \multirow{2}{*}{ Temperature $\left({ }^{\circ} \mathrm{C}\right)$} & \multicolumn{2}{|c|}{ Mobile phase (\%) } \\
\hline & & & Acetonitrile & $1 \%$ Acetic acid \\
\hline 0 & 0.7 & 28 & 10 & 90 \\
\hline 28 & 0.7 & 28 & 40 & 60 \\
\hline 39 & 0.7 & 28 & 60 & 40 \\
\hline 50 & 0.7 & 28 & 90 & 10 \\
\hline 55 & 0.7 & 28 & 10 & 90 \\
\hline 65 & 0.7 & 28 & 10 & 90 \\
\hline
\end{tabular}


spiked standard and the reference mode was turned on critically for identification of integration data analysis. Quantification of each injected sample was completely success by measuring the integrated area. As a result, content number of samples was calculated based on calibration curve by plotting peak area, respective standard sample was also considered. The data were subjected in quadruplicate.

\section{Method validation}

The analytical method was validated according to The International Council for Harmonisation of Technical Requirements for Pharmaceuticals for Human Use guideline, namely, the effectiveness, the limit of detection (LOD), the limit of quantitation (LOQ), the linearity, the precision, and the accuracy, as shown in Table 2. The effectiveness of HPLC method was confirmed by recognizing peak of standard solvent randomly after it was diluted with the diverse solvent. Acetonitrile and $1 \%$ acetic acid resolved well in this study; however, other solvents, such as methanol and formic acid, might be considered. Theoretically, LOD and LOQ were calculated from the calibration curve according to the following equations:

$$
\begin{aligned}
& \mathrm{LOD}=3.3 \times \frac{\sigma}{S} \\
& \mathrm{LOQ}=10 \times \frac{\sigma}{S}
\end{aligned}
$$

where $\sigma$ is the standard deviation of $y$-axis interception values and $S$ is the angular coefficient.

To obtain linearity, a calibration curve was created with a stock standard solution $(1 \mu \mathrm{g} / \mathrm{ml})$ diluted to six concentrations $(5,10,20,30,40$, and $60 \mu \mathrm{g} / \mathrm{ml})$ randomly injected in triplicate. The calibration curve was accepted to get $R^{2}>0.99$ indicating the significantly abundant linearity measurement. Precision evaluation was run repeatability and intermediate precision using the degree of proximity expressing as \% relative standard deviation (RSD) of retention time and peak area. Two diluted concentration was selected (20 and $40 \mu \mathrm{g} / \mathrm{ml}$ ) by injecting in 10 times to evaluate $\%$ RSD determination. The accuracy was evaluated based on the recovery percentage of crude and residue extract spiking to 20 and $40 \mu \mathrm{g} / \mathrm{ml}$. Results of accuracy were calculated in terms of recovery $(\% R)$ according to the following equation:

$$
R(\%)=\frac{\mathrm{a}-\mathrm{b}}{\mathrm{c}} \times 100
$$

where $a$ is the amount found, $b$ is the amount contained, and $c$ is the amount added.

\section{RESULT AND DISCUSSION}

\section{Optimization of chromatographic condition}

The UV-Vis spectrum of all the standard compounds showed successfully in wavelength $272 \mathrm{~nm}$. This wavelength provided a clearest separation of single peak area toward to the retention time. Regardless of time observation, running at 43

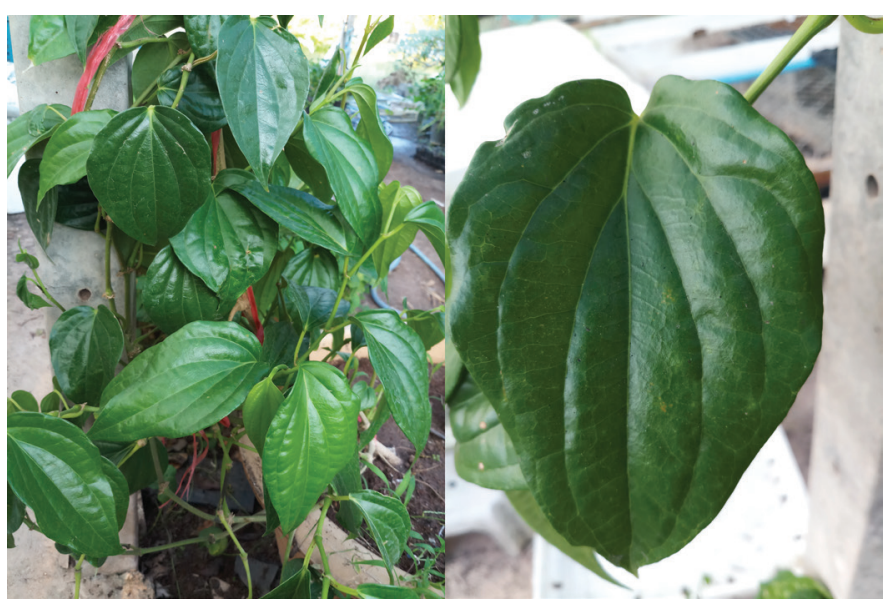

Figure 1. Piper betle Linn. (Family: Piperaceae ).

\begin{tabular}{|c|c|c|c|c|c|c|c|c|}
\hline Standard name & Retention time & $\begin{array}{l}\text { RSD }(\%) \text { of } \\
\text { the retention } \\
\text { time }\end{array}$ & $\begin{array}{l}\text { RSD }(\%) \text { of the } \\
\text { peak area at } \\
\text { conc. } 20 \mu \mathrm{g} / \mathrm{ml}\end{array}$ & $\begin{array}{l}\text { RSD }(\%) \text { of the } \\
\text { peak area at } \\
\text { conc. } 40 \mu \mathrm{g} / \mathrm{ml}\end{array}$ & $\begin{array}{c}\text { Regression } \\
\text { coefficient } \\
R^{2}\end{array}$ & LOD $\mu \mathrm{g} / \mathrm{ml}$ & $\mathrm{LOQ} \mu \mathrm{g} / \mathrm{ml}$ & $\begin{array}{l}\text { Percentage of } \\
\text { recovery } \\
(\%)\end{array}$ \\
\hline Ascorbic acid & 3.74 & 0.277 & 0.602 & 0.074 & 0.9951 & 0.003 & 0.008 & 99.69 \\
\hline Gallic acid & 5.42 & 0.318 & 0.842 & 0.518 & 0.9981 & 0.001 & 0.002 & 100.47 \\
\hline Catechin & 10.55 & 0.502 & 0.291 & 0.220 & 0.9986 & 0.013 & 0.038 & 101.09 \\
\hline Caffeic acid & 13.12 & 0.430 & 0.132 & 0.196 & 0.9990 & 0.003 & 0.008 & 101.94 \\
\hline Syringic acid & 13.60 & 0.436 & 0.171 & 0.222 & 0.9988 & 0.001 & 0.004 & 101.66 \\
\hline Rutin & 16.30 & 0.579 & 0.175 & 0.262 & 0.9990 & 0.006 & 0.018 & 97.52 \\
\hline P-coumaric acid & 17.49 & 0.395 & 0.184 & 0.221 & 0.9984 & 0.002 & 0.007 & 100.80 \\
\hline Sinapic acid & 18.62 & 0.373 & 0.467 & 0.973 & 0.9990 & 0.007 & 0.020 & 98.59 \\
\hline Ferrulic acid & 18.85 & 0.573 & 0.165 & 0.386 & 0.9996 & 0.008 & 0.023 & 102.62 \\
\hline Myrecetin & 22.53 & 0.283 & 0.299 & 0.562 & 0.9955 & 0.001 & 0.004 & 102.78 \\
\hline Quercetin & 27.82 & 0.242 & 0.367 & 0.938 & 0.9910 & 0.001 & 0.003 & 99.86 \\
\hline Apigenin & 32.00 & 0.211 & 0.522 & 0.293 & 0.9915 & 0.012 & 0.035 & 96.02 \\
\hline Kaempferol & 32.90 & 0.205 & 0.957 & 0.276 & 0.9907 & 0.009 & 0.027 & 100.05 \\
\hline Eugenol & 37.49 & 0.221 & 0.148 & 0.171 & 0.9908 & 0.004 & 0.011 & 100.26 \\
\hline
\end{tabular}

Table 2. Retention time and parameters of calibration curve, precision, and repeatability, LOD, LOQ, and percent recovery study of standard ascorbic acid, phenolic acids, flavonoids, and eugenol for HPLC method validation using wavelength at $272 \mathrm{~nm}$. 


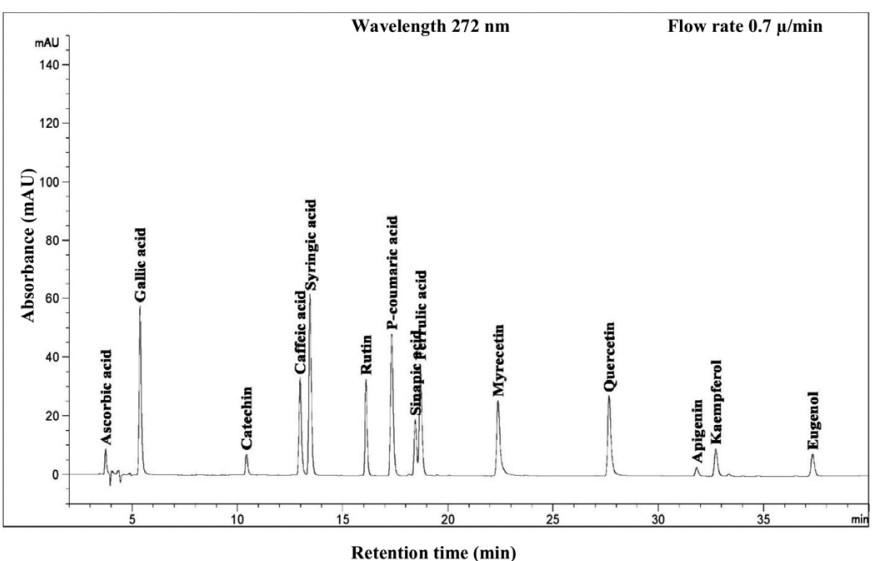

Figure 2. Standard HPLC chromatogram of phenolic compound, water-soluble vitamin, and essential oil.

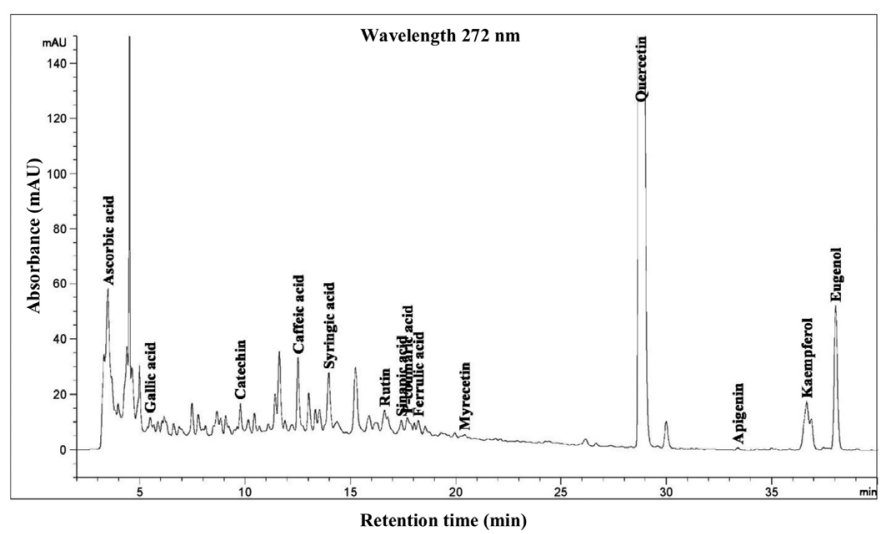

Figure 3. HPLC chromatogram of Piper betle $L$ crude content in water extract.

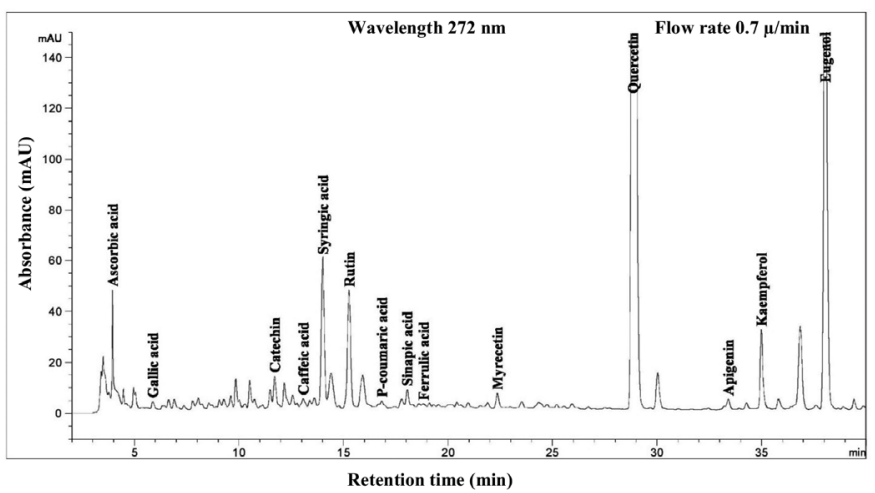

Figure 4. HPLC chromatogram of Piper betle $L$ crude content in methanol extract.

minutes onward was found slightly sensitive identification. All the peak area is depicted in Figure 2.

\section{Validation method of phenolic compound, water-soluble vitamin, and essential oil}

The response of validation method, including linearity, precision, and accuracy is presented in Table 2. A compulsory-

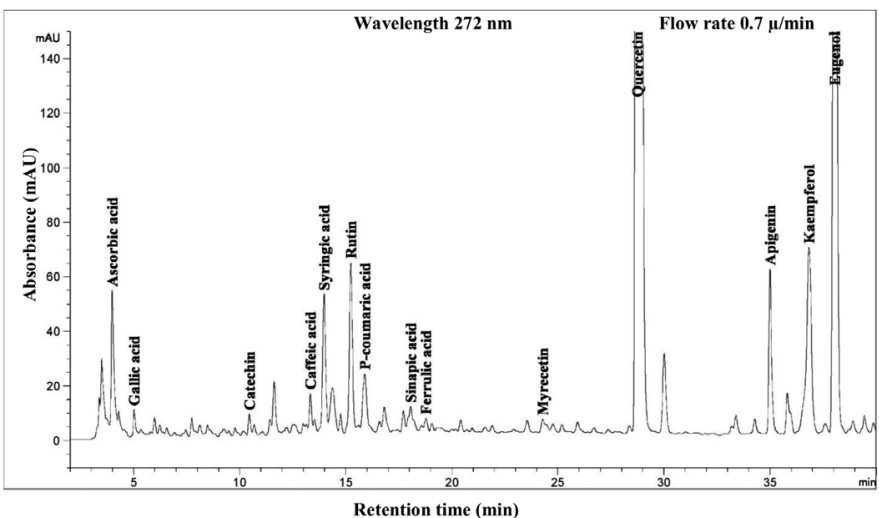

Figure 5. HPLC chromatogram of Piper betle $L$ crude content in ethanol extract.

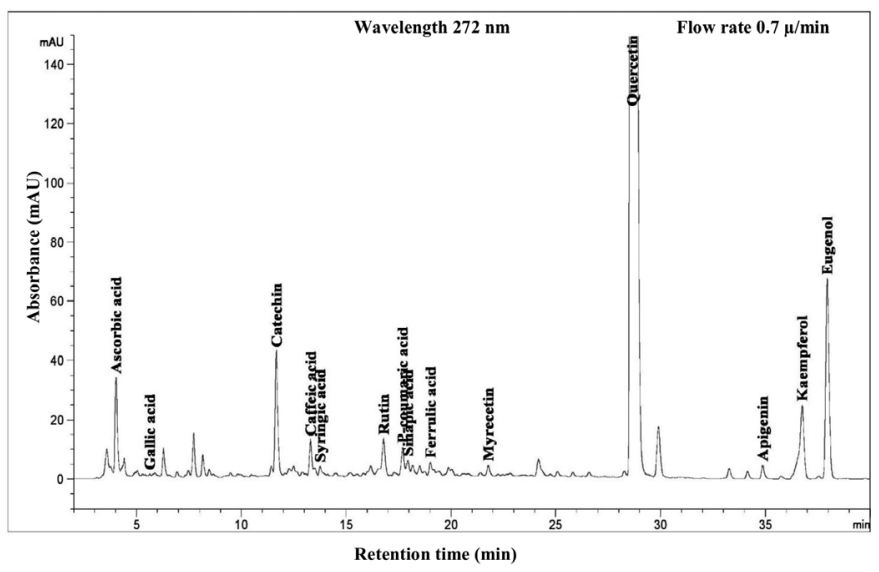

Figure 6. HPLC chromatogram of Piper betle $L$ crude content in chloroform extract.

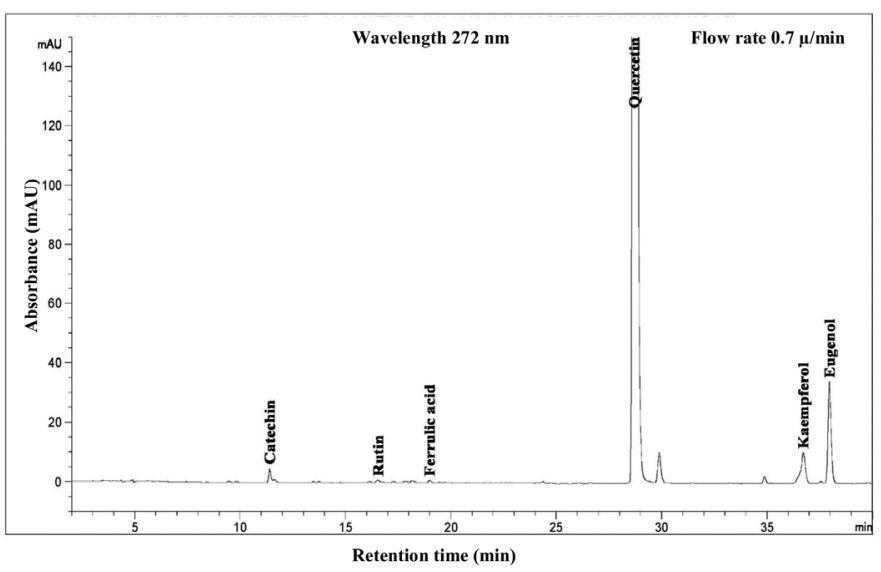

Figure 7. HPLC chromatogram of Piper betle $L$ crude content in hexane extract.

mixed standard chemical was found over $R^{2}>0.9907$ indicating all variables standing on linearity. According to the precision, RSD in retention time and spiking peak area at two selectively standards, 20 and $40 \mu \mathrm{g} / \mathrm{ml}$ were lesser $1 \%$ exhibiting repeatability running a rigid way. An automatically injection valve set maintaining 


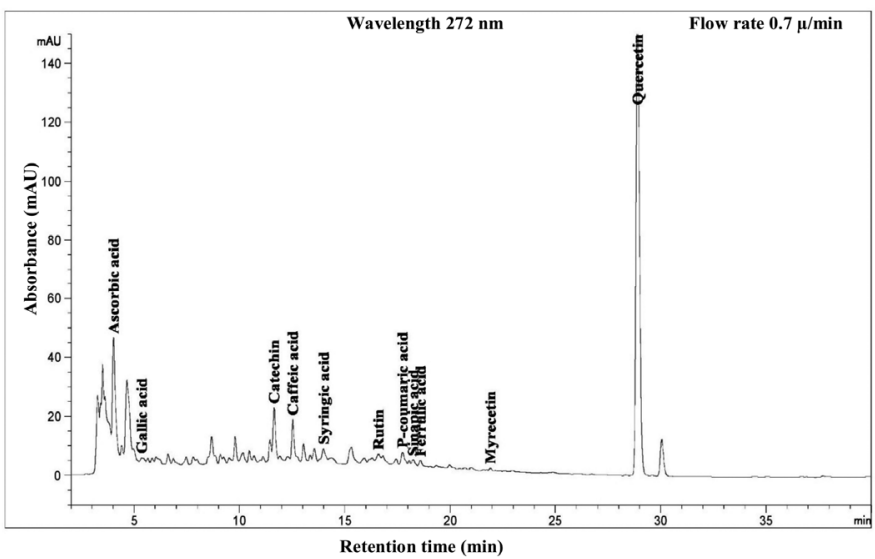

Figure 8. HPLC chromatogram of Piper betle $L$ residue content in water extract.

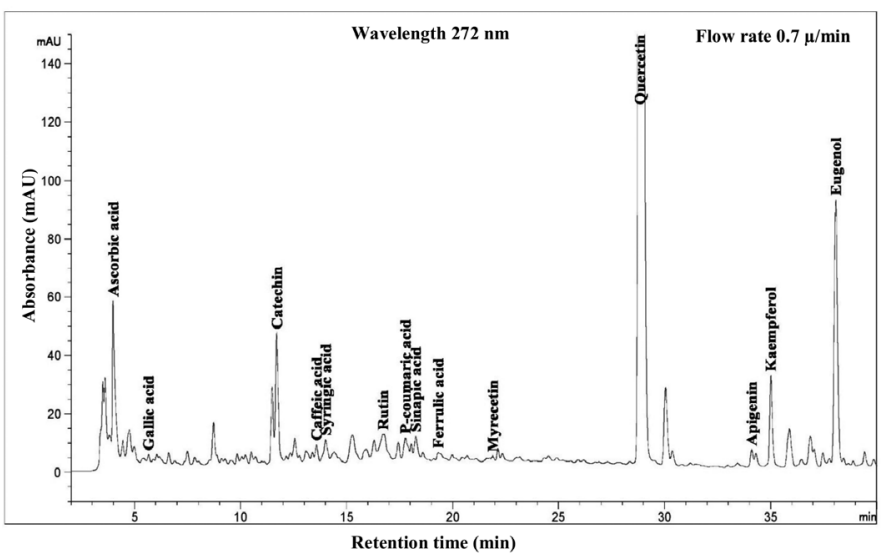

Figure 9. HPLC chromatogram of Piper betle $L$ residue content in methanol extract.betle $L$ residue content in methanol extract.

evaporation off solvent and mixing genuinely vial were acceptable strategies for further recommending investigations. Furthermore, the LOD and LOQ were calculated as mean 0.005 and $0.015 \mu \mathrm{g} /$ $\mathrm{ml}$, respectively. The decreased values of these limits revealed high sensitivity of the method. In this study, the separation detector was set a strictly shorter than previous study (Syahidah et al., 2017), In addition, the percentage of recovery was in the range 96-102. A breakthrough in number was particularly interesting in this stage, considering the method formula hinged on linearity, precision, and accuracy involving meticulousness could be applicated for qualitative and quantitative analysis of phenolic compound, watersoluble vitamin, and essential oil of this study.

\section{Identifying compounds of phenolic compound, water-soluble vitamin, and essential oil}

The phenolic compound, water-soluble vitamin, and essential oil chromatogram of crude content is captured in Figures 3-7 and residue content in Figures 8-12 following by water, methanol, ethanol, chloroform, and hexane, respectively. Clearly, polar solvents were easier to bond the organic compound due to uneven distribution of electron density, while non-polar solvents were opposite sentence. A relationship of $\mathrm{O}-\mathrm{H}$ bonding

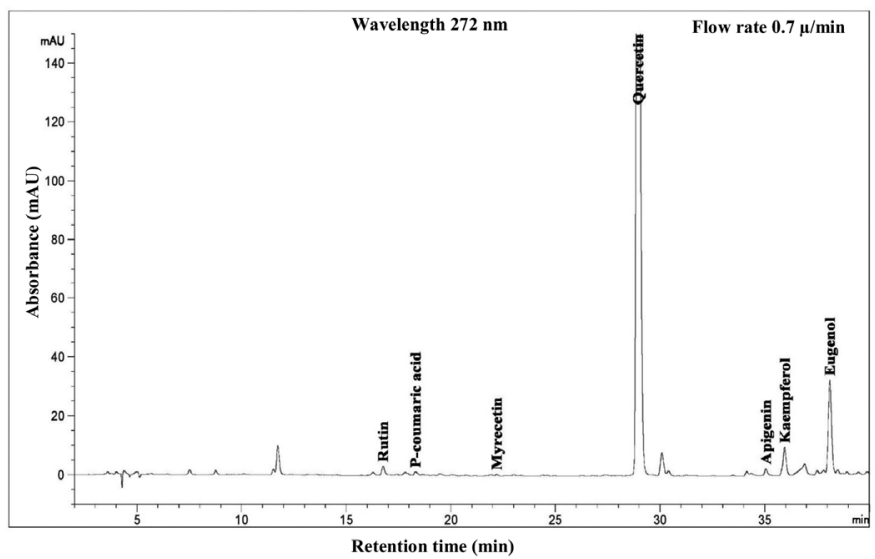

Figure 10. HPLC chromatogram of Piper betle $L$ residue content in ethanol extract.

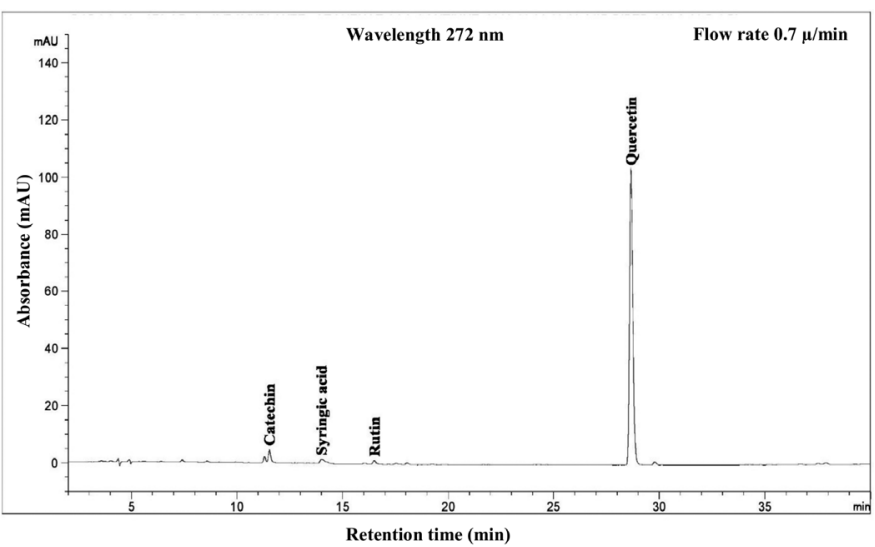

Figure 11. HPLC chromatogram of Piper betle $L$ residue content in chloroform extract.

and repeating extraction might be a hand of effecting factors stimulating compound sensitivity. As a result, flavonoid was most edible dissolved among essential oil and water-soluble vitamin (Rafiq et al., 2018). Overall, quercetin and eugenol were duo foremost in crude-residue contents of the plant under investigation.

Quantifying compounds of phenolic compound, water-soluble vitamin, and essential oil

A completely quantitative result is presented in Table 3. In this present study, the proportion of Piper betle L. chemical compounds from highest to lowest was phenolic compounds, essential oil, and water-soluble vitamin $(\mathrm{mg} / \mathrm{g})$. The most organic compound of phenolic fraction was flavonoids $67.4 \%$ and $55.3 \%$ for crude and residue content, respectively. Eugenol as essential oil representative was only slighter number at $20 \%$ and remaining percentages confirmed as ascorbic acid (water-soluble vitamin). In previous reports, the average percentage $(\%)$ or mass $(\mathrm{mg} / \mathrm{g})$ of various Piper betle L. confirmed eugenol as the most major compound (Begam et al., 2018; Prakash et al., 2010), even Syahidah et al. (2017) adjusted assessment by TLC study that Piper betle L. might have flavonoid or other phenolic compounds. The suitable method for extraction and detection probably 
provided a clearer peak in specifically Piper betle L. quantity $(\mathrm{mg} / \mathrm{g})$. For instance, the handy extraction method of this study promoted obtaining catechin successfully.

Literally, catechin is difficult to extract. The greatest reason because of catechin is lofty sensitivity in oxidation, light alkaline environment, and high temperature (Gadkari and Balaraman, 2015). However, catechin of Piper betle L. was successfully extracted and presented in polar and non-polar solvents using hot reflux extraction (Soxhlet apparatus), see Table 3. There were $\max 0.560 \mathrm{mg} / \mathrm{g}$ using chloroform in crude content and $0.869 \mathrm{mg} / \mathrm{g}$ using methanol in residue content, where these numbers were quite low toward recommendation. Catechin was rich in tea around $20-160 \mathrm{mg} / \mathrm{g}$ and bean 70-110 mg/g (Manach et al., 2004). Meanwhile, other flavonoids were successfully detected, as shown in Table 3.

Along with flavonoid, gallic acid plays role as plant defense. Gallic acid is commonly found and collected from fruits and vegetables. The gallic acid content of this study was found a

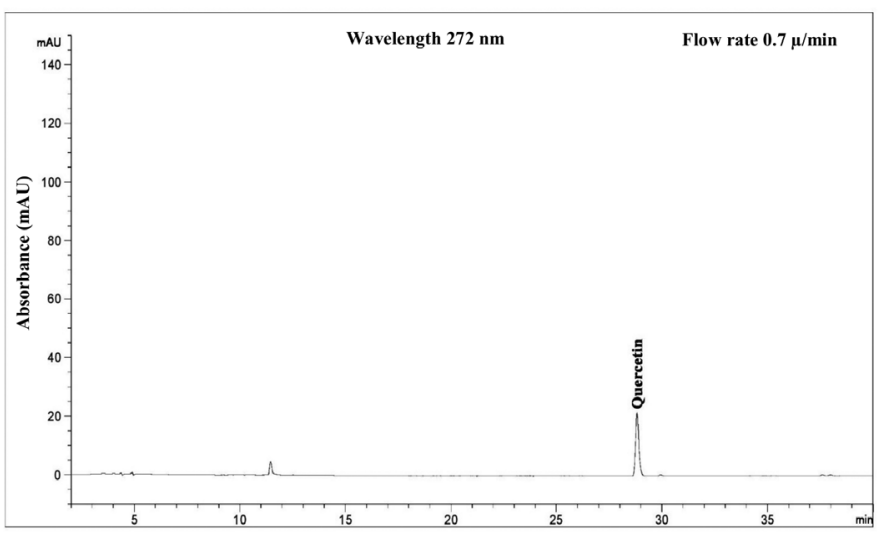

Retention time (min)

Figure 12. HPLC chromatogram of Piper betle $L$ residue content in hexane extract. lesser number in both of crude and residue Piper betle L. content $<0.06 \mathrm{mg} / \mathrm{g}$. Karamac et al. (2006) and Bayili et al. (2011) were reported content gallic acid in plant at least $0.21 \mathrm{mg} / \mathrm{g}$ to provoke the detrimental health problem to antioxidant purpose. Hence, gallic acid was predicted greater sensitive in polar dissolver.

Syringic acid, a final form of benzoic acid derivative, is biosynthesized by $\beta$-oxidation through shikimic pathway which is interfered massively with lignin in plant cell walls (Srinivasulu et al., 2018). Rothwell et al. (2012) reported syringic acid was present in cucumber 0.006 , parsnip 0.011 , and rosemary $0.015 \mathrm{mg} / \mathrm{g}$, while our study addressed the vying numbers around eight times over comparing with rosemary number in both Piper betle L. contents of using polar solvents. In spite of effective solvent, hexane was often failed exposing this organic group. In this study, other cinnamic compounds involving caffeic acid, p-coumaric acid, sinapic acid, and ferulic acid were successfully quantified, as shown in Table 3.

The most famous essential oil for expressing antimicrobial and antiseptic is eugenol (Begam et al., 2018; Syahidah et al., 2017). This phenylpropanoids is ubiquitous commonly extracted from mint leaves and spices. In present study, eugenol was successfully incited by all solvents yet ethanol promoted a mere content about 11.971 $\mathrm{mg} / \mathrm{g}$ that was incredible number examined with other eugenol sources, e.g., nutmeg 0.090, basil 2.154, and clove $156.951 \mathrm{mg} / \mathrm{g}$ (Rothwell et al., 2012). As expected, residue content was lesser eugenol explaining the acceptable method for aforementioned regarding essential oil extraction from Piper betle L.

Ascorbic acid, one of water-soluble vitamins, is simplest vitamin and broadly apparent in fruit and vegetables. This essential vitamin provides functions as enzyme cofactor, hormone biosynthesis, and wound healing in plant and animal metabolism. Davey et al. (2000) reviewed the ascorbic acid played as antioxidant role solving basic oxidative stress in plant and reported Acerola (west Indian cherry) and Roseship contained the highest ascorbic acid 13 and $1 \mathrm{mg} / \mathrm{g}$, respectively. In our study, Piper betle L. crude content using ethanol extract was found lesser $11.5 \%$ of

Table 3. Quantification of ascorbic acids, phenolic acids, flavonoids, and essential oils of Piper betle L. $(n=4)$.

\begin{tabular}{|c|c|c|c|c|c|c|c|c|c|c|}
\hline \multirow{2}{*}{$\begin{array}{l}\text { Compound } \\
\text { names }\end{array}$} & \multicolumn{5}{|c|}{ Piper betle L. crude content (mg/g) } & \multicolumn{5}{|c|}{ Piper betle L. residue content (mg/g) } \\
\hline & Water & Methanol & Ethanol & Chloroform & Hexane & Water & Methanol & Ethanol & Chloroform & Hexane \\
\hline Ascorbic acid & $0.124 \pm 0.068$ & $0.242 \pm 0.023$ & $1.598 \pm 0.051$ & $0.299 \pm 0.044$ & $\mathrm{Nd}$ & $0.454 \pm 0.016$ & $1.062 \pm 0.486$ & $\mathrm{Nd}$ & $\mathrm{Nd}$ & $\mathrm{Nd}$ \\
\hline Gallic acid & $0.008 \pm 0.004$ & $0.049 \pm 0.012$ & $0.080 \pm 0.008$ & $0.049 \pm 0.014$ & $\mathrm{Nd}$ & $0.046 \pm 0.011$ & $0.049 \pm 0.010$ & $\mathrm{Nd}$ & $\mathrm{Nd}$ & $\mathrm{Nd}$ \\
\hline Catechin & $0.029 \pm 0.013$ & $0.248 \pm 0.107$ & $0.245 \pm 0.004$ & $0.561 \pm 0.005$ & $0.036 \pm 0.021$ & $0.260 \pm 0.014$ & $0.869 \pm 0.390$ & $0.096 \pm 0.055$ & $0.109 \pm 0.018$ & $\mathrm{Nd}$ \\
\hline Caffeic acid & $0.017 \pm 0.007$ & $0.058 \pm 0.009$ & $0.120 \pm 0.008$ & $0.060 \pm 0.007$ & $\mathrm{Nd}$ & $0.071 \pm 0.008$ & $0.061 \pm 0.008$ & $\mathrm{Nd}$ & $\mathrm{Nd}$ & $\mathrm{Nd}$ \\
\hline Syringic acid & $0.010 \pm 0.004$ & $0.111 \pm 0.017$ & $0.260 \pm 0.006$ & $0.045 \pm 0.010$ & $\mathrm{Nd}$ & $0.050 \pm 0.009$ & $0.106 \pm 0.016$ & $\mathrm{Nd}$ & $0.007 \pm 0.007$ & $\mathrm{Nd}$ \\
\hline Rutin & $0.009 \pm 0.004$ & $0.187 \pm 0.029$ & $0.697 \pm 0.004$ & $0.089 \pm 0.007$ & $0.010 \pm 0.006$ & $0.047 \pm 0.005$ & $0.187 \pm 0.028$ & $0.042 \pm 0.008$ & $0.011 \pm 0.006$ & $\mathrm{Nd}$ \\
\hline P-coumaric acid & $0.009 \pm 0.004$ & $0.060 \pm 0.016$ & $0.189 \pm 0.013$ & $0.060 \pm 0.011$ & $\mathrm{Nd}$ & $0.053 \pm 0.011$ & $0.071 \pm 0.016$ & $0.014 \pm 0.008$ & $\mathrm{Nd}$ & $\mathrm{Nd}$ \\
\hline Sinapic acid & $0.008 \pm 0.004$ & $0.055 \pm 0.003$ & $0.225 \pm 0.017$ & $0.046 \pm 0.008$ & $\mathrm{Nd}$ & $0.040 \pm 0.007$ & $0.101 \pm 0.025$ & $\mathrm{Nd}$ & $\mathrm{Nd}$ & $\mathrm{Nd}$ \\
\hline Ferrulic acid & $0.005 \pm 0.002$ & $0.029 \pm 0.008$ & $0.055 \pm 0.004$ & $0.031 \pm 0.006$ & $0.007 \pm 0.004$ & $0.008 \pm 0.005$ & $0.030 \pm 0.014$ & $\mathrm{Nd}$ & $\mathrm{Nd}$ & $\mathrm{Nd}$ \\
\hline Myrecetin & $0.011 \pm 0.005$ & $0.082 \pm 0.017$ & $0.121 \pm 0.015$ & $0.073 \pm 0.015$ & $\mathrm{Nd}$ & $0.019 \pm 0.011$ & $0.083 \pm 0.016$ & $0.019 \pm 0.011$ & $\mathrm{Nd}$ & $\mathrm{Nd}$ \\
\hline Quercetin & $0.200 \pm 0.013$ & $4.399 \pm 0.056$ & $13.615 \pm 0.813$ & $8.695 \pm 0.012$ & $3.037 \pm 0.134$ & $0.539 \pm 0.019$ & $5.630 \pm 0.073$ & $1.181 \pm 0.026$ & $0.387 \pm 0.036$ & $0.149 \pm 0.024$ \\
\hline Apigenin & $0.002 \pm 0.001$ & $0.793 \pm 0.132$ & $4.410 \pm 0.069$ & $0.255 \pm 0.057$ & $\mathrm{Nd}$ & $\mathrm{Nd}$ & $0.323 \pm 0.076$ & $0.059 \pm 0.034$ & $\mathrm{Nd}$ & $\mathrm{Nd}$ \\
\hline Kaempferol & $0.007 \pm 0.004$ & $0.545 \pm 0.143$ & $2.371 \pm 0.051$ & $0.669 \pm 0.173$ & $0.346 \pm 0.092$ & $\mathrm{Nd}$ & $0.485 \pm 0.104$ & $0.185 \pm 0.025$ & $\mathrm{Nd}$ & $\mathrm{Nd}$ \\
\hline Eugenol & $0.029 \pm 0.002$ & $1.990 \pm 0.052$ & $11.971 \pm 0.288$ & $1.246 \pm 0.361$ & $0.812 \pm 0.283$ & $\mathrm{Nd}$ & $2.095 \pm 0.072$ & $0.347 \pm 0.013$ & $\mathrm{Nd}$ & $\mathrm{Nd}$ \\
\hline
\end{tabular}

ND: Non-detected.

Data are presented as Mean \pm SEM. 
Acerola content, which was equivalent with guava content $2 \mathrm{mg} / \mathrm{g}$, whereas Piper betle L. residue content using methanol was only 1 $\mathrm{mg} / \mathrm{g}$. However, the non-polar solvents were repeatedly failed to provoke ascorbic acid in crude-residue contents that indicated the slightly polar unrecommending used in this way.

\section{CONCLUSION}

The reversed-phase HPLC-DAD was successfully used for identification and quantification of phenolic compound, water-soluble vitamin, and essential oil of Piper betle L. extract in different polarity of solvents. The method demonstrated more compatible with complex compounds involving ascorbic acid, gallic acid, catechin, caffeic acid, syringic acid, rutin, p-coumaric acid, sinapic acid, ferrulic acid, myricetin, quercetin, apigenin, kaempferol, and eugenol, thereby, promising a simple procedure with more efficiency. LC-MS and FTIR synchrotron technique may be considered for further investigation. Consequently, this method could be applied, repeated, and developed for later observation and the present value of Piper betle L. could be recommended for problem solving in pharmaceutical biotechnology community (quality control units), human nutrition, and animal welfare group.

\section{ACKNOWLEDGMENTS}

The authors would like to thank Prof. Emeritus Dr. Nantakorn Boonkerd, Sim Wei Chung, and all staffs of Chemical and Biochemical Analysis Division, Molecule Unit, Suranaree University of Technology. Rayudika Aprilia Patindra Purba acknowledges the Suranaree University of Technology scholarship for ASEAN phase II (No. MOE5601/1350) as fund source.

\section{REFERENCES}

Bayili, RG, Abdoul-Latif F, Kone OH, Diao M, Bassole IHN, Dicko MH. Phenolic compounds and antioxidant activities in some fruits and vegetables from Burkina Faso. Afr J Biotechnol, 2011; 10:13543-7.

Begam, KMF, Ravichandran P, Manimekalai V. Phytochemical analysis of some selected varieties of Piper betle L. Int J Curr Pharm Res, 2018; 10:89-93.

Dasgupta, N, De B. Antioxidant activity of Piper betle L. leaf extract in vitro. Food Chem, 2004; 88:219-24.

Datta, A, Ghoshdastidar S, Singh M. Antimicrobial Property of Piper betel Leaf against clinical isolates of bacteria. Int J Pharm Sci Res, $2011 ; 2: 104-9$.

Davey, MW, Montagu MV, Inzé D, Sanmartin M, Kanellis A, Smirnoff N, Benzie IJJ, Strain JJ, Favell D, Fletcher J. Plant L-ascorbic acid: chemistry, function, metabolism, bioavailability and effects of processing. J Sci Food Agric, 2000; 80:825-60.

Gadkari, PV, Balaraman M. Catechins: sources, extraction and encapsulation: a review. Food Bioprod Process, 2015; 93:122-38.

Karamac, M, Kosiñska A, Pegg RB. Content of gallic acid in selected plant extracts. Pol J Food Nutr Sci, 2006; 15:55-8.

Lin, D, Xiao M, Zhao J, Li ZY, Xing B, Li X, Kong M, Li L, Zhang Q, Liu Y, Chen H, Qin W, Wu H, Chen S. An overview of plant phenolic compounds and their importance in human nutrition and management of type 2 diabetes. Molecules, 2016; 21:1374.

Manach, C, Scalbert A, Morand C, Rémésy C, Jiménez L. Polyphenols: food sources and bioavailability. Am J Clin Nutr, 2004; 79:727-47.

Prakash, B, Shukla R, Singh P, Kumar A, Mishra PK, Dubey NK. Efficacy of chemically characterized Piper betle L. essential oil against fungal and aflatoxin contamination of some edible commodities and its antioxidant activity. Int J Food Microbiol, 2010; 142:114-9.

Rafiq, S, Kaul R, Sofi SA, Bashir N, Nazir F, Nayik AG. Citrus peel as a source of functional ingredient: a review. J Saudi Soc Agric Sci, $2018 ; 17: 351-8$.

Rothwell, JA, Urpi-Sarda M, Boto-Ordoñez M, Knox C, Llorach R, Eisner R, Cruz JM, Neveu V, Wishart D, Manach C, Andres-Lacueva C, Scalbert A. Phenol-explorer 2.0: a major update of the phenol-explorer database integrating data on polyphenol metabolism and pharmacokinetics in humans and experimental animals. Database, 2012; 2012:031-1.

Seal, T. Quantitative HPLC analysis of phenolic acids, flavonoids and ascorbic acid in four different solvent extracts of two wild edible leaves, Sonchus arvensis and Oenanthe linearis of North-Eastern region in India. J Appl Pharm Sci, 2016; 6:157-66.

Srinivasulu, C, Ramgopal M, Ramanjaneyulu G, Anuradha CM, Kumar CS. Syringic acid (sa) - a review of its occurrence, biosynthesis, pharmacological and industrial importance. Biomed Pharmacother, 2018; 108:547-57.

Syahidah, A, Saad CR, Hassan MD, Rukayadi Y, Norazian MH, Kamarudin MS. Phytochemical analysis, identification and quantification of antibacterial active compounds in betel leaves, Piper betle methanolic extract. Pak J Biol Sci, 2017; 20:70-81.

\section{How to cite this article:}

Purba RAP, Paengkoum P. Bioanalytical HPLC method of Piper betle L. for quantifying phenolic compound, watersoluble vitamin, and essential oil in five different solvent extracts. J Appl Pharm Sci, 2019; 9(05):033-039. 